\title{
Corrigendum: Orthology Analysis and In Vivo Complementation Studies to Elucidate the Role of DIR1 during Systemic Acquired Resistance in Arabidopsis thaliana and Cucumis sativus
}

\author{
Marisa Isaacs ${ }^{1 \dagger}$, Philip Carella ${ }^{1 \dagger}$, Jennifer Faubert ${ }^{1}$, Marc J. Champigny ${ }^{2}$, \\ Jocelyn K. C. Rose ${ }^{3}$ and Robin K. Cameron ${ }^{1 *}$ \\ ${ }^{1}$ Department of Biology, McMaster University, Hamilton, ON, Canada, ${ }^{2}$ Department of Molecular \& Cellular Biology, \\ University of Guelph, Guelph, ON, Canada, ${ }^{3}$ Plant Biology Section, School of Integrative Plant Science, Cornell University, \\ Ithaca, NY, United States
}

Keywords: cucumber, DIR1, hydrophobic cavity, lipid transfer protein, long-distance signaling, systemic acquired resistance

\section{OPEN ACCESS}

Edited and reviewed by:

Frontiers in Plant Science,

Frontiers, Switzerland

*Correspondence:

Robin K. Cameron

rcamero@mcmaster.ca

${ }^{\dagger}$ These authors have contributed equally to this work.

Specialty section

This article was submitted to Plant Microbe Interactions, a section of the journal Frontiers in Plant Science

Received: 10 March 2018 Accepted: 22 March 2018 Published: 12 April 2018

Citation:

Isaacs M, Carella P, Faubert J,

Champigny MJ, Rose JKC and Cameron RK (2018) Corrigendum:

Orthology Analysis and In Vivo Complementation Studies to Elucidate the Role of DIR1 during Systemic

Acquired Resistance in

Arabidopsis thaliana and Cucumis sativus.

Front. Plant Sci. 9:460.

doi: 10.3389/fpls.2018.00460

\section{A corrigendum on}

Orthology Analysis and In Vivo Complementation Studies to Elucidate the Role of DIR1 during Systemic Acquired Resistance in Arabidopsis thaliana and Cucumis sativus

by Isaacs, M., Carella, P., Faubert, J., Rose, J. K. C., and Cameron, R. K. (2016). Front. Plant Sci. 7:566. doi: $10.3389 / \mathrm{fpls.2016.00566}$

An author who contributed to this paper was mistakenly left off the author list. The corrected author and affiliation lists, plus the author contribution statement are indicated below.

Marisa Isaacs $^{1 \dagger}$, Philip Carella ${ }^{1 \dagger}$, Jennifer Faubert ${ }^{1}$, Marc J. Champigny ${ }^{2}$ Jocelyn K. C. Rose ${ }^{3}$ and Robin K. Cameron ${ }^{1 *}$

${ }^{1}$ Department of Biology, McMaster University, Hamilton, ON, Canada, ${ }^{2}$ Department of Molecular \& Cellular Biology, University of Guelph, ${ }^{3}$ Plant Biology Section, School of Integrative Plant Science, Cornell University, Ithaca, NY, United States.

\section{AUTHOR CONTRIBUTIONS}

MI and PC contributed equally as first authors. Designed experiments: MI, PC, MC, JR, and RC. Performed experiments: MI, PC, MC and JF. Analyzed data: MI, PC, MC, JF, and RC. Provided reagents and equipment: JR and RC. PC and RC wrote the bulk of the manuscript, with significant contributions by MI and JR.

The original article has been updated.

Conflict of Interest Statement: The authors declare that the research was conducted in the absence of any commercial or financial relationships that could be construed as a potential conflict of interest.

Copyright (๑) 2018 Isaacs, Carella, Faubert, Champigny, Rose and Cameron. This is an open-access article distributed under the terms of the Creative Commons Attribution License (CC BY). The use, distribution or reproduction in other forums is permitted, provided the original author(s) and the copyright owner are credited and that the original publication in this journal is cited, in accordance with accepted academic practice. No use, distribution or reproduction is permitted which does not comply with these terms 